Journal of Ancient Philosophy Vol. VI 2012 Issue 1

\title{
Socratic Eudaimonism and Natural Value
}

Naomi Reshotko (University of Denver)

Socratic Eudaimonism gives us a model that a naturalist concerning ethics can follow in order to establish a natural "goal state" for human behavior. With this goal state established, the notion of value for a human being falls out of the relationship between that goal state and the natural world. Socrates thought that the maximal state of flourishing that a human being can achieve could be understood with respect to this natural goal state, and that the actualization of this natural goal is the only standard needed or possible for the evaluation of everything other than it with respect to goodness, badness, rightness or wrongness.

Eudaimonia for Socrates is the natural and inevitable goal of all human activity and thus, the good for all human beings. The importance of Socratic eudaimonism for contemporary moral philosophy is that it allows for the naturalization of the notions of good and bad and right and wrong and the elimination of any notion of value-hence, any notion of morality - that cannot be naturalized.

To have a notion of morality that cannot be naturalized is to have to explain why something is good or bad or right or wrong without recourse to some brute fact about human nature, human psychology and the way that they interface with the way that the world happens to be. There are at least two reasons to resist a defense of value in the absence of naturalism. First, it makes it impossible to avoid the conclusion that right and wrong are, at some level, arbitrary, as Socrates demonstrates in the Euthyphro. Second, it makes it impossible to give a satisfying explanation for why human beings are motivated to do what is right, and so, impossible to cultivate the desire to be moral in a person who doesn't already have it. I will address these two claims in more detail in a moment. 
When I say that Socratic Eudaimonism provides for the naturalization of value, I do not mean to imply that either the historic Socrates or the Socrates that Plato portrays in his dialogues believed in only what we today call the "natural" world," or that he was a naturalist when it comes to ethics. ${ }^{1}$ There is evidence-even in the strictly "Socratic" dialogues - that Socrates believed in divinities and in other supernatural things. I suspect that Socrates thought true eudaimonia was a divine state toward which human beings strive in an effort to fulfill their divine nature. ${ }^{2}$ My claim is that Socrates gives us a model that a naturalist concerning ethics can follow in order to establish a natural "goal state" for human behavior and to show how, once such a goal state is established, the notion of value for a human being can fall out of the relationship between that goal state, and the natural world. What is important to the argument of the present paper is that Socrates thought that the maximum that a human being could achieve is something that has a component a sufficiently natural—rather than supernatural—state or activity for a human being, and that the actualization of this natural goal is the only standard needed or possible for evaluation of everything other than it in terms of goodness, badness, rightness or wrongness.

Socratic eudaimonism eliminates any notion of value that cannot be naturalized by putting together six theses:

(1) Eudaimonia is an objective state.

(2) Every human being, by nature, inevitably strives to attain eudaimonia.

(3) Knowledge is the major determining factor in one's success at achieving eudaimonia.

\footnotetext{
${ }^{1}$ I do think that a subset of the Group I dialogues can be singled out as displaying a distinct and coherent ethical and psychological theory that is at odds with some things found in the Group II and III dialogues. I think that it makes sense to suppose that these views originated with the historical Socrates, but I have no investment in the truth of that claim. Nothing philosophical hangs on the attribution of this view to Socrates; it could be that Plato is arguing for one view of his own creation in the Group I dialogues and changed his mind about salient features of that view in other dialogues.

${ }^{2}$ But I do not plan to go into this view in detail here. See n. 6, below.
} 
(4) Nothing other than eudaimonia and its opposite (human misery) has any value that is independent of its ability to advance or deter eudaimonia in the particular context in which that other commodity is used.

(5) It is always, primarily, our own eudaimonia that we seek.

(6) Pursuit of our own eudaimonia necessitates concern for the well-being of others.

I will thread these six theses together briefly before moving on to show how Socrates advances and integrates them in more detail: Socrates sees eudaimonia as an objective state that every human being inevitably, by nature, strives to attain; all people desire and seek their own good and eudaimonia is human good. This inevitable striving for an objective eudaimonia is paired by Socrates with a notion of human psychology that understands knowledge to be the determining factor in how successful one is at reaching that objective eudaimonic state. One is trying to accomplish an objective task-far more complicated than, but not, in principle, unlike climbing Mt. Everest-and whether or not one is successful is a consequence of the combination of one's resources, one's physical condition, one's skill, who one chooses (or is thrown together with) as colleagues in the effort, and the external conditions one is subject to during the particular time during which one makes the attempt. The more comprehensive one's knowledge, the more likely one is to succeed or to approximate success. But this knowledge is of the actual features and properties of all of the components that one must employ in order to do the deed. It does not include knowledge of what is "good" or "bad" in some abstract sense, all that is necessary is knowledge of what is "good" for the completion of one of the many subtasks in which the super-task consists; what is the best method or the best means (of those that are available) for getting a certain job done. All actions and objects-in fact everything other than human happiness and human misery-have no value independent of the circumstances of their use. Their value is a consequence of how they are used and what results from their use. Their value is determined by the degree to which their use 
enhances or detracts from the eudaimonia of the person who uses them. ${ }^{3}$ Deliberate actions are done for reasons and having a reason, according to Socrates' understanding of human psychology, amounts to seeing an action as beneficial to oneself. But, understanding what is beneficial to oneself includes the realization that harming others is a poor strategy for achieving long-term benefit.

\section{The Euthyphro Dilemma and Universal Moral Truths}

The weakness of seeing good and bad as originating in a divine decree or otherworldly "fact" is revealed in the Euthyphro. Upon being asked what is pious, Euthyphro (eventually) replies with "what is loved by the gods" (10d-11c). Socrates probes this answer further asking "is a thing pious because the gods love it, or do the gods love it because it is pious?" This is a destructive dilemma against the supposition of divine decree: It can't be the case that what is good or morally right is so only because God said so. For how did God choose what would be right and what would be wrong? It seems absurd to think that God chose arbitrarily; that murder was condemned through some fluke of God's own little lottery and could just as easily have been condoned. But if God did not choose arbitrarily, than God must have looked to something that dictated which things were already right and wrong. If that's what God did, then right and wrong do not result from God's decree.

\footnotetext{
${ }^{3}$ Thus a consequence of this "naturalized" view is that the natural world has no independent value as far as human beings are concerned. Of course natural beings other than humans might have a best state that they strive to be in for their own sake. But, naturalism in ethics dictates that it is best for human beings if the natural world is in the state most conducive to human eudaimonia. When we worry about such things as nuclear war and global warming, we aren't really worried about the health of the earth - the earth will be just fine in the long run, it is not even clear that mere human beings can destroy the earth. When we say that we are concerned about the health of the earth, we are saying that we are concerned that the earth continues to be a place where human beings can be healthy and eudaimonic.
} 
Many do assume that Plato's desired conclusion in the Euthyphro argument is that there is something like universal moral truth. ${ }^{4}$ But if we take the Euthyphro dilemma seriously-and resonate with the notion that a morality determined arbitrarily is not compelling-then we should be no more satisfied with universal moral truths than we were with the notion of divine decree. How did the universal moral truths come to be and what made them, as opposed to their opposites, the definition of good and bad and right and wrong? If we can't answer these questions, then it is unclear how we can persuade people to be invested in and to adhere to these supposed truths.

Neither divine decree nor universal moral truths can connect the evaluations of actions as good and bad with an explanation for why human beings are or should be motivated to do what is good and avoid what is bad. When naturalized along Socratic lines however, this sort of explanation is forthcoming. Human beings strive for the good-as measured by eudaimonia-because it is a law of nature. It is like explaining why objects fall toward the center of the earth through the theory of gravity - a theory about the inter-relationships and interactions among the various components of the natural world-rather than by saying "because God makes them fall in that direction" or "because that's just the way the world is." Thus, it is not that Socratic eudaimonism motivates people to seek and do what is good. Rather, it analyzes human motivation toward anything whatsoever as originating from the motivation to do and seek the good. It analyzes our failure to do and obtain the good as a breakdown in our appreciation of what the good is and a breakdown in our understanding of the obstacles, over which we have little or no control, that need to be overcome in the process of becoming eudaimonic or at least as eudaimonic as possible. Further, once we understand our own natural

\footnotetext{
${ }^{4}$ However, anyone who thinks it is a hint at Plato's introduction of the Form of the Good would have a variety of ways of looking at it, some of which do not necessarily reduce to a notion of universal moral truth. Someone who takes it this way could understand it along the lines that I will suggest here. Although, it is my suspicion that the dialogue only commits Socrates to viewing the good as a feature of the natural world; as something like benefit or, in the case of human beings, eudaimonia.
} 
motivation toward eudaimonia, it encourages us to do whatever we can to make it more likely that we will get it.

\section{Eudaimonia: the Bare Bones that make for Naturalism}

To say that, for Socrates, eudaimonia is "objective" is to say that it is possible for each person to be mistaken about what eudaimonia is. It is possible for each person to be wrong about whether or not eudaimonia is what he or she is currently experiencing: being happy is not the same thing as thinking that one is happy. Furthermore, thinking that a particular action or object will lead to happiness or that a particular object, action or psychic or physical activity is constitutive of happiness is also no guarantee that it does or is. It does not follow that eudaimonia is the same for every person nor is that ruled out as a possibility. ${ }^{5}$ It does follow that eudaimonia consists in some specific and determinate physical and or psychic activities and or circumstances in each person's case. This is compatible with, but not sufficient to dictate, the view that happiness is a kind of pleasure. $^{6}$

There is a risk in comparing the attainment of eudaimonia to climbing Mt. Everest, as I did earlier. The worry is that my reader will assume that the analogue for being eudaimonic is being at the peak of Mt. Everest. This assumption must be dispelled. The point of using something like climbing Mt. Everest as an analogue for the pursuit and

\footnotetext{
${ }^{5}$ There is no need to take a stand on this in the present argument. I do think that Socrates thought that while people are eudaimonic under different circumstances and while performing different activities, eudaimonia has some universal qualities. I hope to address this in a forthcoming article "Platonic and Socratic Sophia and Eudaimonia and their Facsimiles."

${ }^{6}$ While I do think that it can be argued that Socrates thought eudaimonia was a species of nonsensate pleasure (see my 2006, 179-183 where I argue for a very specific subset of what Rudebusch argues for in his 2001, 81-96 and 123-128). The thesis that eudaimonia is pleasure is not essential to the claim that Socrates has succeeded in naturalizing ethics (pace Wolfsdorf $2006 \mathrm{~b}, 4)$. What is required is that eudaimonia is objective, that goods are commensurable (see my 2006, 185-186 for arguments to this effect), and that eudaimonia is the sort of thing that Aristotle (E.N., X.iv, 1174a14-b9, Met. 1048b18-34) would have called an activity rather than a movement.
} 
attainment of eudaimonia is that what it is to climb Mt. Everest is not determined by how one thinks or talks about what one is doing, it is an objective task at which one can fail in a few relevant ways. One can fail by mistaking some other mountain-Mt. Evans, perhaps-for Mt. Everest. If one manages to get to the peak of Mt. Evans, thinking that one has conquered Mt. Everest, one has in no way accomplished anything with respect to the task of climbing Mt. Everest. The fact that one might never find out that it was not Mt. Everest, or that no one else ever finds out, makes no difference. Climbing Mt Evans is not climbing Mt. Everest. Also, there are many further ways in which Mt. Everest- the determinate and existent geographical feature-constrains one's interaction with it and attempt to climb it. While one might need to be in the right state of mind in order to succeed, climbing or having climbed Mt. Everest is not identical to being in a certain state of mind.

I want to convey that eudaimonia is an objective goal, but I don't want to convey that it is the same kind of objective as being at the peak of Mt. Everest. Socrates did not see eudaimonic experience as "peak" experience. He saw it more along the lines of what we might call "optimal" experience. The notion of optimal experience is compatible with there being a series of many "peaks." The present moment is the peak that we are experiencing right now and the next moment is the peak for which all of our past moments, and the present one, have been a preparation. A wise person who happens to be a person for whom climbing Everest would enhance eudaimonia experiences eudaimonia (or approximates it to a variety of degrees ${ }^{7}$ ) while planning the trip to Everest, while training, while acclimating in base camp, and while deciding to stop short of the peak and turn back. There is an objective shape that we strive for each moment of our experience to embody, and the human quest is to see that every moment comes as close as possible to having that shape. In our wisdom we might also calculate that it is worth spending some moments in rather suboptimal activities (recovering from surgery or enduring

\footnotetext{
${ }^{7}$ It is actually my view that Socrates thought no human being actually experiences eudaimonia but rather a facsimile of it that can be thought of as a non-sensate pleasure (this is a thesis of my future article "Platonic and Socratic Sophia and Eudaimonia and their Facsimiles" as well). But for the purposes of this paper, I will simply be content to imply that the facsimile is eudaimonia.
} 
Journal of Ancient Philosophy Vol. VI 2012 Issue 1

chemotherapy) in the service of being able to spend more future moments more optimally. ${ }^{8}$ If eudaimonia is about the shape of each moment, and each moment involves planning and preparing for the eudaimonia of future moments, then deliberating, reasoning, calculating, etc. must all be compatible with-if not also constituents ofeudaimonia. So Socrates envisioned eudaimonia as either compatible with well-informed rational deliberation, stemming from such deliberation, conducive to it, or all of the above.

This is all that is necessary for Socratic eudaimonia to be the sort of goal that will allow Socrates to naturalize ethics. Plato notoriously and frustratingly has Socrates tell us very little directly about the nature and identity of eudaimonia. I will endeavor to justify no more about it than what I have already said is necessary to the thesis that I now promote.

While Socrates never comes out and says what eudaimonia is and never states in so many words that eudaimonia is objective, he makes arguments in several dialogues that are designed to show that our pursuit of both our own happiness and the happiness of our children is premised on the assumption that happiness is objective. It is common for a section of dialogue to heighten our awareness of the fact that just doing whatever it seems to one will make one happy won't make one happy.

Samples occur at Lysis 207d5-209c6, Meno 88a3-88c4 and Euthydemus 279d6280a8. In the Lysis passage, the interchange between Socrates and Lysis underlines the fact that because they want him to be happy, Lysis' parents permit him to do what he wants only in areas where he has knowledge, leaving him most often to be controlled by a guardian or a teacher and leaving most of their own property to be controlled by slaves who have knowledge concerning its proper use. Lysis is permitted to do whatever he

\footnotetext{
${ }^{8}$ Thus, while I do not commit Socrates to the view_criticized by Aristotle (E.N. 1153b17-21) and adopted by the Stoics - that the virtuous person is happy even while enduring horrible torture and misfortune, I do think that Socrates thought that the virtuous person was more able to handle these experiences than his less virtuous counterpart and that the virtuous person would "bounce back" to a higher degree of eudaimonia than his counterpart would, were he to survive misfortune.
} 
wishes when it comes to the order of writing letters and the tautness or slackness with which he tunes the lyre, but that is because he knows something about how to order letters and tune lyres in ways that are objectively more beneficial than others.

In the Meno and Euthydemus passages it is pointed out that having resources at one's disposal does not lead to one's happiness; one must use them (Euthydemus 280b-d), but moreover, must use them correctly (Meno 88a3-88c4, Euthydemus 280e5-6) with knowledge of how they interact causally with other things. Using them incorrectly could lead to misery and not to happiness (Euthydemus 281d2-e1). In the Charmides, Socrates also makes it clear that the more scientifically knowledgeable one is, the happier one will become (174ab). In fact the most widely accepted claims about Socrates-that he believed that virtue simply was knowledge and that virtue was the key to happinessnecessitate the conclusion that happiness is something that one needs knowledge in order to recognize and acquire and thus that happiness can't be identified with just anything a person happens to think that it is. ${ }^{9}$

Socrates also indicates, several times, that it takes an expert to evaluate a person's happiness. Some people think they are happy and might even seem happy to others when, in fact, they are not. Some examples are the jury in the hands of the Olympian victors in the Apology (36e) and the Great King in the Gorgias (470e4-11). If some people are better than others at recognizing happiness, both in others and in themselves, then happiness must be some particular, determinate thing, concerning which it is possible for one person to have more scientific expertise than another.

Throughout the dialogues, but particularly in the Euthydemus (279e-280a), Socrates compares the endeavor to become happy to the development and use of a skillful activity like navigating, flute playing, practicing medicine, writing, reading and military strategizing. Notable about skillful activities is that they are productive in a twofold manner. They are processes that lead to products that are distinct from themselves: fluteplaying produces music, medicine produces health. And they are processes that lead to

\footnotetext{
${ }^{9}$ See Gerson (5) on this topic.
} 
their own acquisition and improvement. The way to learn to play the flute is by playing the flute, the way to improve one's flute-playing is through playing. Even those flute players who have reached the pinnacle of virtuosity continue to "practice" and continue to improve. The endeavor to maintain the quality of, or to improve, one's future fluteplaying is not distinct from one's current playing. It doesn't matter whether one is momentarily "practicing" or "performing," the activity that one is doing is not separate from the activity that affects one's future playing of the flute. ${ }^{10}$ So, one's current playing is both an activity producing one's present product (music) and one providing for the quality of one's future playing and, therefore, one's future product.

If the activity of leading a eudaimonic life or "doing well" (as Socrates frequently calls it) is itself a skillful activity and has features that are analogous to other skillful activities, then it would be reasonable to assume that Socrates is thinking that our momentary efforts to produce current eudaimonia are the same efforts that will allow our future moments to either be, or not be, eudaimonic. Thus, our efforts to learn and our knowledgeable deliberations and calculations of what it is best for us to do in the future both constitute and are instrumental for the production of both present and future eudaimonia.

\section{Eudaimonia: the Inevitable Object of Our Desires and Pursuits}

In introducing the textual evidence for the objectivity of eudaimonia, I showed Socrates to be demonstrating our agreement with the claim that "just doing whatever it seems to one will make one happy won't make one happy." The phrase "doing whatever it seems to one will make one happy" is a non-technical way of expressing an important observation that Socrates makes. Socrates finds it necessary to allow for a degree of disconnection between what we actually do in order to become happy and what we want when we do what we actually do in order to become happy. Socrates sees us as naturally

\footnotetext{
${ }^{10}$ Even if the effect it has is to make one's future playing worse (because one develops bad habits or plays in such a way as to compromise one's future embouchure).
} 
"programmed" to pursue whatever is our own good. As human beings, that good is eudaimonia. But Socrates does not think that it is always clear to us that we seek our own good and he certainly doesn't think that we know what that good that we seek is. Thus, Socrates recognizes that the processes of (1) actively seeking one's own good, (2) identifying one's own good, (3) identifying what one is doing (that one is questing after one's own good) and (4) figuring out how one is to seek one's own good, all overlap: they take place simultaneously and are served (or at least constituted-and often not wellserved) by the same behavior. In order to account for this Socrates must hold a complicated - rather messy even - theory of desire. But he has no alternative. How lovely and simple things would be if only we already knew that we were seeking our own good before we had to figure out what that good was, and if we already knew what our own good was before we had to go about finding it. If only the success of each of these processes didn't rely on a product of at least one of the others. If only all we had to do while seeking the good was to seek the good, then seeking one's good could be a much simpler process where one took one's attractions to various things at face value and set out to figure out the best way to satisfy one's desires. But that is not the position that we are in on Socrates' account.

Socrates realizes that the fact that we are doing all of these sequentially interdependent exercises at the same time-and not sequentially-is a big problem. It impedes the success of our quest, but it also impedes our ability to analyze that quest. Due to this realization concerning our human predicament, Socrates attaches desire to the actual good as opposed to the merely apparent good. What an agent actually desires need not be what she thinks she desires at all. Socrates takes every agent to desire whatever is actually best for her. That is, whatever will best advance her eudaimonia at the moment at which she acts. One way to think of this is that Socrates takes each agent, in each situation, to want what she would have seen herself as wanting had she first successfully figured out that she wanted the good, then that her good was eudaimonia, then what her eudaimonia consisted in and finally what actions on her part would best lead to that eudaimonic goal. Agents make errors in figuring out what they desire because 
they don't have the requisite knowledge. Their desires always aim at whatever is actually best for them, but, in their ignorance, agents err appallingly at interpreting both their own desire and its object. Thus, while everyone desires what is actually good for them (Meno $77 \mathrm{~b} 2-78 \mathrm{~b} 6)^{11}$ they often do only what seems best to them rather than what they wish to do (Gorgias 466a-468e). ${ }^{12}$

In the Gorgias, Socrates distinguishes between doing what we want to do and doing what only seems best to us. A desire ${ }^{13}$ can make us do either one. But even when the desire causes us to do what only seems best to us, that same desire is for what was actually best for us. What becomes clear through Socrates' employment of the distinction between doing what we want and doing what seems best to us is that Socrates understands desires to be three-place relations between an agent, the action that the agent actually performs and some further goal that the agent hopes to achieve by performing that action. The further goal is always connected to the goal of doing what is actually good-namely whatever will bring the best available outcome in the agent's current situation. But an agent's ignorance-her false beliefs-can create any number of mismatches between the action chosen and the goal of doing whatever is actually best in the current situation. This mismatch allows the desire for the actual good to direct the agent toward some intermediate goal that is not actually conducive to doing what is best. For example, I might eat a chili pepper that is so hot that having it in my mouth causes severe pain. What I now want and what is now actually best for me is to reduce the pain in my mouth. The pain is a burning sensation and often, when my mouth burns, a drink

\footnotetext{
${ }^{11}$ There is a history of controversy concerning the Meno passage with respect to whether or not the claim therein is that all desire is for the actual good. See Santas 1979, 185-189; Penner and Rowe 1994; Anagnostopoulos and Wolfsdorf 2006a.

${ }^{12}$ Even those who are convinced that the Meno shows all desire to be for the apparent good, agree that the Gorgias passage is at odds with that claim. See Santas 2003, 99; Anagnostopoulos, 186-191 and Wolfsdorf 2006a, 79.

${ }^{13}$ It is important to understand the kind of desire in question as a desire that causes a specific action to happen; my more general desire to write an article functions in such a way that it, together with my beliefs and other desires results in the desire to type a particular letter. It is the desire to type the particular letter that Socrates is interested in when he claims that desire is for the actual good.
} 
of cold water helps to ease the pain. But, even though they feel the same in the mouth, burning caused by food that is hot in temperature and burning caused by the chili pepper have-unbeknownst to me-very different physical properties and, therefore, very different antidotes. I do not realize that the water will simply spread the oil from the pepper evenly around my mouth and will not rinse it away. Thus, the water will, if anything, increase the pain in my mouth. Still, not having this information, I think that drinking water is the best thing I can do in this situation. So, I go ahead and do it. But, Socrates would say that drinking water, because it did not reduce the pain in my mouth, was not what I actually wanted. It is only what-in my ignorance-seemed best to me. Nonetheless, my desire for what is actually good (the reduction of the pain in my mouth) still explains why I drank the water. For it was my goal of doing whatever was actually best for me-whatever would reduce the pain — that combined with my misapprehension about the oil in the chili pepper to cause my drinking of the water. I had what we might think of as an incoherent desire, it was for something other than drinking water (I'm told that either milk or beer works well) but it directed me toward the water so it looked as if it was a desire for water.

So, we see that, just as Socrates found eudaimonia to have objective identity conditions, so also, desire has objective features according to him. A particular subject is not necessarily an expert on whether or not she is happy, nor does she necessarily have any special expertise in determining what she wants. The action that is actually best for her in her current situation (even though she likely doesn't know what it is) plays a role in determining what she actually wants. Another way of saying this is that the consequences of the action she actually performs are part of the identity of that action and, so, play a role in determining whether or not it is the action she actually wanted to perform. ${ }^{14}$

\footnotetext{
${ }^{14}$ In his recent defense of the "subjectivity" of the notion of desire found in the Meno, Wolfsdorf (2006a) has the originator of the views in that dialogue (be it Socrates or Plato) embrace a subjective notion of desire (79) at the same time and in the same dialogue as he embraces an objective notion of happiness ("However, this is compatible with the view that happiness consists of having truly good things," 89). Thus, Wolfsdorf's Socrates (or Plato) considers psychological activities piecemeal: either neglecting to relate desire and happiness as instances of a general phenomenon about which it might behoove one to have some sort of a consistent theory or
} 


\section{Knowledge: the Determining Factor in Eudaimonia}

Given Socrates' theory of desire, it is easy to see why he thinks that it is knowledge (which he deems arete or "virtue") and not desire or intention that is the determining factor in the extent to which a person becomes eudaimonic. Everyone is the same when it comes to what they desire or intend to do-they all intend to do whatever is actually best in their current situation. In the earlier cited Lysis passage it is a tacit assumption that since Lysis knows how to order letters in what has been pre-established as a beneficial way, and how to tune the lyre in a pre-established beneficial way, he will endeavor to follow his knowledge and not to order the letters or tune the lyre haphazardly. The tacit assumption is that once one knows what is beneficial one will seek to do it. One never seeks to do something that one does not consider to be the most beneficial action overall. So knowledge of what is beneficial is the key to doing and getting what is beneficial.

We see this same sentiment in the Hippias Minor, where once it has been determined that a man who voluntarily does wrong must be wiser than he who only accidentally does wrong,Socrates says that the good man is the one who would voluntarily do wrong, if indeed any wise man would do such a thing ("If there be such a man." 376b5-6). The good man is the most capable of doing wrong voluntarily-the most able to choose that which is disadvantageous from among the choices available, for that is tantamount to being able to choose the most advantageous alternative. Knowledge

deciding against it. Wolfsdorf likely does not find it legitimate to take this sort of thing into consideration, as he would claim it imports unwarranted epistemological assumptions (2006b, 45). Surprisingly, Wolfsdorf thinks his own "primarily philological and historical approach" makes no such assumptions and is a completely neutral tool for uncovering "genuine historicity" (5). That any interpretive tool is devoid of bold metaphysical and epistemological assumptions would seem a naive claim. For a rehearsal of the reasons why logic and philology are laden with metaphysical and epistemological baggage see Penner 2007, 17-19. For an argument that Plato would have found them to have this baggage see Penner 1987, 287-299 
is what enables one to calculate advantage and disadvantage, but the result will always be that the most advantageous alternative is chosen.

It is in the Euthydemus and the Charmides that Socrates makes it clearest that knowledge — of everything and not some special "moral" knowledge—is the key to happiness. In the Euthydemus, Socrates is asked to explain to Cleinias why one should endeavor to become as knowledgeable as possible (275a). The conclusion of the argument is that one is most likely to fulfill one's wish to do well if one has knowledge (280b-282e). Knowledge is the only way that a person can exert any control whatsoever over whether or not she becomes happy. Just as knowledge is the only way that a doctor can exert any control over the health of a patient and the only way that a navigator can maintain any control over the success of a voyage (279e-280a). This is the case because, as we said before, what constitutes each person's happiness is determined by objective criteria and only knowledge of our own natures and of what the world within which we must pursue our happiness is like will allow us to discover that we are seeking happiness, what our happiness consists in, and how me might choreograph our activities so that we might reach it.

In the Charmides, Socrates investigates whether there is any particular kind of knowledge that allows a person to become happy. He concludes that while someone who is completely scientific and is ignorant of nothing (173e-174a) would be the person most able to arrive at happiness, this person would not use all of her knowledge equally, and she would rely on knowledge of past, present and future good and bad the most. So Socrates thinks that while the knowledge of good and bad is used the most in making oneself happy, it would not be able to do so in the absence of complete scientific knowledge. His reasons for thinking that knowledge of past, present, and future good and bad will be most valuable in figuring out how to make ourselves happy in the future become obvious when we think about what he thinks good and bad are. Good is happiness or whatever is best able to further happiness (the current optimal experience that is optimal partly because it leads to the future optimal experience) and the bad is whatever detracts from happiness (both this moment's and what it stores up for future 
moments). So knowing past and present good and bad is understanding the causal relationships between our former actions and what has come to pass; understanding, through careful and critical analysis, which actions have led to which consequences and what results for our well-being have accrued from them. People who observe and analyze the data with which they are presented in light of their knowledge of the fact that a determinately constituted state of well-being is what is best for them and that what is best for them is what they are endeavoring to pursue are those who come to know past and present good and bad. The extent to which they know past and present good and bad is the extent to which they are reliable predictors of future good and bad.

Unfortunately, as previously noted, we are in a dismal epistemological situation. Our eudaimonia depends on four pursuits that ideally would be done sequentially but that have to take place at once. Ideally we would come to know what happiness is and how to attain it first, so seeking knowledge would be the first step to seeking happiness. Once we had knowledge we would just go about making our calculations and deliberations and putting it all together in one lovely package. But we have to pursue knowledge and happiness at the same time even though we must use one in the pursuit of the other. Still, the pursuit of knowledge is the first step-indeed it is the only voluntary step we can take-in the pursuit of happiness.

\section{Eudaimonia and its Opposite: the Only Things with Non-relational Value}

Eudaimonia is the goal that we are all naturally and inevitable programmed to pursue. It is the only such goal. Knowledge is not pursued naturally and inevitably, it is pursued by those who have come to understand that it is the only purposeful means toward increasing one's well-being. Because we are programmed by nature to pursue eudaimonia (and to avoid its opposite), eudaimonia and its opposite are the only things that have a natural value that comes from their own nature, they have the only natural value that is not derived from the value of something else. Since eudaimonia is always a good thing for a human being, goodness is its natural value. Since the opposite of 
eudaimonia is always detrimental, badness is its natural value. Thus, eudaimonia is the only human activity that is naturally good and its opposite is the only one that is naturally bad.

Knowledge is also a special commodity, but not because it is naturally and inevitably good. Socrates has argued at $R p$. 333e-334a and throughout the Hippias Minor (by claiming that Odysseus was more knowledgeable than Achilles as he "erred" voluntarily) that knowledge — raw knowledge—is ambivalent. The same knowledge that allows someone to protect money in a bank allows that person to steal the money. But, Socrates' emphasis on the fact that all desire is for the actual good means that no human being ever possesses raw knowledge—no human being ever possesses knowledge that functions outside of the framework laid out by her desire for the good. So, given that everyone wants what is actually best for them-whatever actually puts them on the road to genuine eudaimonia - and given that knowledge is what allows us to discern what is actually best for us, knowledge is always beneficial to a human being. So knowledge, as it is always combined with the desire for the good, is unconditionally good; it is good in all conditions and under every circumstance. But, knowledge is not good due to its own nature, it is good because of the relationship that it has to human eudaimonia. Because human desire naturally sets eudaimonia as its goal, making it the natural good, and knowledge-by its nature - allows a human to achieve whatever goal she has, knowledge will always be connected to eudaimonia and so the natural goodness of eudaimonia extends its glow of natural goodness down upon knowledge: knowledge always increases happiness. So happiness is the reason why knowledge is always good. Happiness is always good and it is naturally good. Knowledge is always good and it is good because human desire makes it have this special law-like relationship with human happiness. ${ }^{15}$

We see Socrates' contention that happiness and knowledge get their goodness in different ways at Euthydemus 278e3-281e1. The discussion between Socrates and his interlocutor is premised on the assumption that everyone wishes to do well (278e3-6)

\footnotetext{
${ }^{15}$ For an extended argument concerning the difference between eudaimonia's good and virtue's, see my 2006 122-125.
} 
from there they move on to the presupposition that things benefit us—are "good"-when they make us happy (280b5-8). Throughout the passage, the criterion of whether or not a possession or an activity leads to our happiness is the litmus test that Socrates uses in determining whether or not that thing is good. At 280d3-4 Socrates states that a man who has all goods but makes no use of them would not be "happy due to his possession of these goods." Socrates examines possession, use and virtuous use as to whether or not each is beneficial and in each case the determining factor is whether that thing leads to happiness $(280 \mathrm{~d} 6,280 \mathrm{e} 1,282 \mathrm{a} 2)$. The promotion of happiness is clearly the natural measure against which all potential goods are measured in the Euthydemus and the winner by a long shot is knowledge; it is the only thing that always engenders happiness and the thing that must be added to the others in order to make them more likely to bring happiness about as well. But knowledge has been measured in accordance with its ability to promote happiness. That is why it is deemed exceptional-happiness makes knowledge the fine thing that it is.

Nothing else in the world, no object and no other human activity is either good due to its own nature or always good. All actions and objects are only conditionally good; the same object can be used to benefit oneself or to harm oneself and the same activity can be a part of two different actions-one with good consequences and one with bad. When these activities or objects are done or used so as to make their agents better off, we call them good. Thus, in these circumstances, they, too, become good due to their circumstantial relationship to eudaimonia. Eudaimonia casts its glow down upon them and they, by association with it, share-however temporarily-in the natural goodness that it alone possesses.

That everything other than knowledge, virtue and their opposites is neither good nor bad is rehearsed in many Group I dialogues. At Gorgias 467e6-468a4, Socrates puts together a sloppy list of those things that are sometimes good, sometimes bad, or neither: "sitting, walking, running, making sea voyages, sticks and stones and the like." ${ }^{16}$ At

\footnotetext{
${ }^{16}$ For an argument that this list, because it is random, is intended to refer to all objects and activities, see my 2006, 30-1 and 97-8.
} 
Euthydemus 280e5-281e1, Socrates and Cleinias compile a list of things that Cleinias takes to be good only to conclude that the only thing on the list that is not just as bad as it is good is wisdom (281e2-5). The same sentiment is also expressed at Meno 87e5-88a3. At Laches 195c Laches and Nicias agree that there is no more reason to dread sickness than there is to dread health for both are neither good nor bad and, depending on the circumstances, a person might be better off remaining in his sickbed, or even dying, for it is not preferable to live for every person in every case. ${ }^{17}$

\section{It is Always Our Own Eudaimonia That We Seek}

So we now see that, on Socrates' view, all value is derived from the one thing that is good by its own nature and that thing has natural value for human beings because it is what they, by their nature, naturally and inevitably seek. Socrates' notion of natural value can be extended and systematized into a theory of what makes human behavior good and bad (or "right" and "wrong") because a natural connection is maintained between each person's automatic efforts to find and maintain eudaimonia and everything that they do in their lives even insofar as that which they do is connected to the well-being of others.

A way to see and understand this is to see eudaimonia as analogous to something like the physiological notion of homeostasis. To see it perhaps as a multi-dimensional analogue to homeostasis that includes that physiological notion along with other dimensions that some would choose to describe as psychological ${ }^{18}$ and, or spiritual. Just as we can fully describe the behavior of a very simple organism solely in terms of its departure from and efforts to return to homeostasis, so Socrates sees every act we do, including those that appear to be done for the benefit of other people, as part of our own

\footnotetext{
${ }^{17}$ See my 2006, 103-115 for a walk through the complexities of the neither good nor bad in the Lysis.

${ }^{18}$ Perhaps we could increase the breadth of the term "psychological" by understanding it as a Greek word (psuche-logicos) and not sticking with its more narrow English academic usage.
} 
efforts to pursue and maintain our own personal eudaimonia. Socrates is a psychological egoist.

No matter how we understand the argument that all desire is for the good at Meno $77 \mathrm{~b} 2-78 \mathrm{~b} 6$, it requires us to equate good with self-benefit and bad with self-harm. ${ }^{19}$ At Gorgias 466a-466e, Socrates' entire argument to the conclusion that Tyrants have the least power in the city is premised on the assumption that power is only power if it is selfbeneficial. In that same dialogue Socrates also argues that justice benefits the self (474c4$\mathrm{d} 2,475 \mathrm{~b} 3-\mathrm{d} 6$ ) and that it is valuable because it is better for the agent than its alternative (470e4-11). At Republic 346a-347c, he suggests that in cases where a person appears to be practicing justice solely for the benefit of others the person in question is actually doing so for monetary remuneration or in order to avoid the worst punishment of allbeing ruled by one worse than oneself. In the Protagoras (351b3-357e8) Socrates describes all deliberation concerning voluntary action as a cost/benefit analysis concerning which alternative is most beneficial for the agent. Throughout the Apology, Socrates refers to his own benefit many times in explaining why he did what he did throughout his life and also why he defends himself as he does (22e5-6, 31d8-e1). Further, he assumes that the jury will make decisions according to their own advantage (19a, 30c-31a).

What makes Socratic Egoism the finishing touch on a well-developed selfregulating system, and so the key to a complete theory of natural value, is the way in which it dovetails with Socrates' view of human desire. Socrates' view explains actual physical behavior through recourse only to desires and beliefs that can be integrated with our desire to benefit ourselves. Any ethic or theory of value that requires human beings to do something that is independent of their own good requires them to have desires that are not connected to this sort of physiologically-modeled, equilibrium-seeking feedback system. A theory that includes desires that are not connected to this sort of system cannot be naturalized. It cannot be naturalized because it cannot explain how executable desires

\footnotetext{
${ }^{19}$ Or at least apparent self-benefit and apparent self-harm.
} 
that are independent of our beliefs concerning what is good for us come about and how they come to be integrated with our beliefs and our motivational system in such a way as to be acted upon. In order to explain any specific instance of behavior-like buying and chewing a stick of gum-we need to explain all of its details. Why was it purchased in the store in which it was purchased or at the time at which it was purchased? Why that brand and not another? Why do I put it in my purse and take out a stick to chew only once I have returned to my office? Such explanations are only forthcoming when the action of purchasing and chewing the gum is understood in terms of other larger goals under which it is subsumed and those goals are understood by being ultimately subsumed under and tied into our desire to do whatever is best for us in our current situationwhatever is most conducive to our eudaimonia. Socrates' realization of this explains why he also is convinced that no one ever willingly performs an action other than the one that they, at least momentarily, believe is best for them in their present circumstances, a stance that he argues for at Protagoras $351 \mathrm{~b} 3-357 \mathrm{e} 8 .^{20}$

\section{Pursuit of Our Own Eudaimonia Necessitates Concern for the Well-being of Others}

All of this egoism and desire for our own good might make it seem that this naturalization of value really isn't very useful after all. Having a theory that says that anything is valuable so long as it makes its possessor or perpetrator happy seems to allow anyone to do whatever selfish, harmful and despicable acts they please, if they will bring them some benefit. But Socrates' psychological egoism is supported by a further view concerning human nature and the natural world. Socrates argues that it is either very risky or impossible to pursue eudaimonia by harming others. He believes that we are all interconnected in such a way that it would be foolish to think that one is likely to benefit by harming others. He maintains that every time we think we can benefit by harming another, we are wrong. The act that we think will be beneficial to us will actually turn out

\footnotetext{
${ }^{20}$ For a thoroughgoing explication of Socrates' argument and a defense of the plausibility of his position, see my 2006, 74-91.
} 
to harm us in the long run, or we are mistaking the benefit that will accrue to another as the result of our action for harm. Some things might appear to be harmful-especially at first—when they are actually beneficial in the long run.

When Socrates defends himself against the charge that he has corrupted the youth of Athens in the Apology, he argues that he would never have corrupted them purposefully, because he knows that anyone who is harmed is made worse by that harm and bad people are likely to bring harm to those who associate with them (258c8-5). In Republic I, 335b2-c7, he again points out that a just man would not harm another man because harming anything or anyone makes them worse in exactly those respects in which they would otherwise excel. The special virtue of human beings is justice, so harming a human being would make the person harmed less just. Why would just people want to do anything to make their fellow human beings less just? Human beings are best served when they are surrounded by those who are just. Later in Republic I, it is agreed that no person, group of people, or city can accomplish any project that requires the cooperation of others unless they treat those others well (351c-d). Treating others badly gives rise to factions and internal conflict and a group that is beset by these ills will not be able to function.

Of course, a person may amass wealth and power through harming others, but wealth and power do not guarantee eudaimonia. In fact, the person who is wealthy and powerful, but ignorant, will suffer as a result (Euthydemus 280e5). Now one might think that a person could benefit by harming another if he simply made sure never to have further interactions with that person after harming him. But this is easier said than done. The person who has suffered harm is also connected to others and may-due to his own increased unjustness-proceed to harm others. These others might be harder for the original perpetrator of harm to recognize and might be plentiful enough that they are hard for anyone to avoid. The more people I need to avoid, the more I need to separate myself from the society at large.This compromises my potential happiness both because it is harder to live a happy life in isolation and also because any time I limit my activities through attempting to avoid particular people or places I lessen the choices that are 
available to me when I deliberate over which is the best possible action for me to perform in my present circumstances.

Socrates gives additional reasons for thinking that we cannot benefit by harming others. In many places (Republic 353d-354a, Crito 48a-d, Gorgias 472c-481b) he says that when we harm others we harm our own souls. Now that sounds more mystical and harder to naturalize than the notion that when we harm others we make them more likely to harm us, but there is a naturalistic way to understand this mechanism as well. Socrates thinks that what allows us to be happy is our virtue-our knowledge. Socrates could think that when we harm others in the belief that we will benefit, we corrupt our own understanding of human nature and the way the world is put together. We mislead ourselves into thinking that such a thing works and will make us better off. We allow ourselves to think that the things we can accomplish through harming others-the accumulation of power and wealth and other things that are actually neither good nor bad-constitute eudaimonia. And if Socrates is right about everything else, then that is the worst possible kind of ignorance to have and to feed.

\section{Conclusion}

Socrates sees human behavior as governed by a natural, self-regulating, system of checks and balances that, in the knowledgeable person, will allow that person to come as close as possible to the achievement of the natural goal of eudaimonia as her external circumstances will permit. This eudaimonia is not a peak experience that occurs at the end of her life, it is something that shapes each moment of her experience so that the cumulative effect is that she has lived as much of her life as possible as close to eudaimonia as possible. I specify "as close as possible" and "as her external circumstances will permit," because each person pursues eudaimonia while embedded in the natural world and in a human civilization that is not of her own making and over which she has limited control. 
Despite the fact that this natural self-regulating system that governs human behavior does so by motivating people to pursue their own personal eudaimonia, Socrates believes that the checks and balances in the natural and human-inhabited world make it the case that it is at least foolhardy, if not impossible, to attempt to obtain one's own eudaimonia at the expense of another's. Thus Socrates' theory of human motivation and purposeful behavior is also a theory concerning what prompts human beings to do what is good for themselves and for others. It is a theory of naturalized value and one that grounds what it is right for human beings to do in observations concerning human nature and the way it inevitably interacts with the natural world.

Is it meaningful to say that Socrates has given us a model for naturalizing ethics by starting from the premise that what is good is simply the goal that humans naturally and inevitably seek? Doesn't this built-in and hard-wired end-state have to have some basis for being called "good" other than the fact that contingent historical circumstances resulted in an organism that strives for a particularly rich (when viewed from a human perspective) state of equilibrium? Doesn't there also have to be some more exterior basis for its goodness? Perhaps that the state is god-like or has been prescribed by God?

It could be that Socrates-or at least Plato-did ultimately have some sort of otherworldly justification in mind: we strive for eudaimonia because we strive for divinity. But first, the Euthyphro argument should give us pause. For there, Socrates argues that the divinity of eudaimonia cannot provide an ultimate source or foundation for goodness. That dialogue invites us to think that divinity and universality are empty solutions to the problem of how to make something good.

Further, for those who look to Socrates only to provide a model for the naturalization of value, the step of justifying the brute and contingent fact that eudaimonia is the end state for a human being is unnecessary: in the same way that it is unnecessary to have an "ultimate" explanation for why electrons migrate from inner shells to outer shells of atoms, and atoms combine with each other, "in order" to form a pattern of two electrons in the first shell and eight in the second shell. Naturalization is what it is-an explanation with recourse only to the natural world, because it describes a 
law abiding system whose foundation is an interdependent group of brute and contingent facts.

\section{Bibliography}

Anagnostopoulos, M. (2003), "Desire for the Good in the Meno", in Reshotko N., ed., (2003) Desire, Identity, and Existence (Edmonton: Academic Printing and Publishing), 171-191.

Penner, T. (1987), Ascent From Nominalism, (Dordecht: Reidel).

Penner, T. (2007), "The Death of the So-called "Socratic Elenchus," in Erler, M., Brisson, L., eds., Gorgias-Menon: Selected Papers from the Seventh Symposium Platonicum, (Sankt Augustine: Academia Verlag), 3-19.

Penner, T. and Rowe, C. (1994), "The Desire for the Good: is the Meno inconsistent with the Gorgias?" Phronesis 39.1, 1-25.

Reshotko, N. (2006), Socratic Virtue: Making the Best of the Neither-Good-nor-Bad (Cambridge University Press).

Santas, G., (1979), Socrates (London: Routledge).

Santas, G., (2003), "Penner, Plato, and Sachs on Justice and Happiness," in Reshotko, N. ed., (2003), Desire, Identity and Existence (Edmonton: Academic Printing and Publishing), 95-107.

Wolfsdorf, D. (2006a), "Desire for Good in Meno 77b2-78b6," Classical Quarterly, 56.1, 77-92.

Wolfsdorf, D. (2006b), Review of Socratic Virtue: Making the Best of the Neither-Goodnor-Bad, by Naomi Reshotko, Notre Dame Philosophical Reviews (http://ndpr.nd.edu/ review.cfm?id=8503; August 28, 2007). 